\title{
Outcome of Patients with Pathological Tumor Stage T3 Urothelial Carcinoma of the Bladder following Radical Cystectomy in a Single-Center Series with 116 Patients
}

\author{
Johannes Breyer ${ }^{a} \quad$ Stefan Denzinger ${ }^{a} \quad$ Wolfgang Otto ${ }^{a} \quad$ Johannes Bründla \\ Michael Gierth ${ }^{a}$ Hans-Martin Fritsche ${ }^{a}$ Wolfgang Rößler ${ }^{a} \quad$ Wolf F. Wieland $^{a}$ \\ Christian Giedl $^{\mathrm{b}}$ Ferdinand Hofstädter ${ }^{\mathrm{b}}$ Peter Rubenwolf ${ }^{\mathrm{c}}$ \\ Maximilian Burger ${ }^{\mathrm{a}}$ Atiqullah Aziz ${ }^{\mathrm{a}}$ \\ ${ }^{a}$ Department of Urology, Caritas St. Josef Medical Center, and ${ }^{b}$ Department of Pathology, University of Regensburg, \\ Regensburg, and ${ }^{\mathrm{C}}$ Department of Urology, Johannes Gutenberg University of Mainz Medical School, Mainz, Germany
}

\section{Key Words}

Bladder carcinoma · E-cadherin · Pathological stage T3 ·

Pathology · Prognostic factors · Radical cystectomy

\begin{abstract}
Objective: Outcome prediction of $\mathrm{pT} 3$ urothelial carcinoma of the bladder (UCB) after radical cystectomy (RC) remains challenging. The objective of our study was to determine high-risk patients with poor survival outcome in a heterogeneous group substaged pT3 who might profit from early adjuvant chemotherapy. Materials and Methods: We compiled clinicopathological and immunohistochemical data of E-cadherin (E-cad) expression in 116 patients with pT3 UCB after RC in our single-center series. Multivariable Cox regression models including substaged pT3 established clinicopathological features, and the expression of the predictive immunohistochemical feature E-cad was used to identify independent predictors on progression-free (PFS), cancer-spe-
\end{abstract}

cific (CSS) and overall survival (OS), respectively. Results: No significant differences were found addressing clinicopathological data and substaged pT3. In multivariable Cox regression models, lymph node involvement was an independent predictor for PFS $(p<0.001)$, CSS $(p<0.001)$ and OS $(p=$ 0.002 ), respectively. Lymphovascular invasion (LVI) significantly influenced PFS $(p=0.016)$. ASA score $3 / 4$ independently predicted CSS $(p=0.049)$ and OS $(p=0.032)$. Neither PT3 substages nor E-cad expression were significant prognosticators for survival. Conclusions: In pT3 UCB patients with ASA 3/4, positive lymph node status and/or presence of $\mathrm{LVI}$, administration of chemotherapy should be considered due to the high risk of poor oncological outcome. The immunohistochemical marker E-cad was not an independent predictor.

(c) 2014 S. Karger AG, Basel

Johannes Breyer and Stefan Denzinger contributed equally to this study.

\section{KARGER}

E-Mail karger@karger.com

www.karger.com/uin
(C) 2014 S. Karger AG, Basel

0042-1138/14/0933-0311\$39.50/0
Dr. Johannes Breyer

Department of Urology

Caritas St. Josef Medical Center, University of Regensburg

Landshuter Strasse 65, DE-93053 Regensburg (Germany)

E-Mail jbreyer@ caritasstjosef.de 


\section{Introduction}

Urothelial carcinoma of the bladder (UCB) represents one of the most common malignancies of the urinary tract and is the fourth most common cancer in men [1]. Roughly $25 \%$ of the initially diagnosed UCB are already in a muscle-invasive or metastatic stage and are therefore associated with a poor prognosis [2]. To date, the gold standard in surgical therapy of high-risk non-muscle-invasive and muscle-invasive UCB remains radical cystectomy (RC) and pelvic lymph node dissection [3].

In 1997, the American Joint Committee on Cancer (AJCC) modified the TNM staging system for bladder cancer substaging pathological tumor ( $\mathrm{pT}$ ) stage 3 into microscopic (pT3a) and macroscopic (pT3b) infiltration of the perivesical fat [4]. Subsequently, several authors presented their findings addressing the prognostic impact of pT3a versus pT3b tumors [5-11]. However, data addressing this issue is far from conclusive and still under debate. While some study groups were unable to detect any difference in survival [5-8], others demonstrated a prognostic relevance of the substaging revision and integrated the substaged pT3 in assessment tools [9-11].

In outcome prediction for UCB, the calcium-dependent transmembrane glycoprotein E-cadherin (E-cad) is ascribed a major role as tumor invasion suppressor [12]. A decrease or lack of E-cad expression is associated with an advanced stage of UCB with higher risk of regional lymph node metastasis and inferior survival rates [13].

Therefore, the aim of the present study was to identify predictors of outcome in the heterogeneous population of pT3 UCB within a range of established clinicopathological features and E-cad expression in a single-center cohort following $\mathrm{RC}$ based on statistically rigorous analysis. Thus, we sought to unmask pT3 UCB patients at an increased risk of poor cancer-specific (CSS) or progression-free survival (PFS), which would allow us to perform a better stratification for the administration of adjuvant treatment and tailored surveillance after RC.

\section{Patients and Methods}

\section{Study Population}

After obtaining local ethics committee approval, the clinicopathological data of 429 consecutive patients undergoing RC and pelvic lymph node dissection for high-risk non-muscle-invasive or muscle-invasive UCB by selected surgeons at one academic urological center from 1989 to 2010 were assessed. All pT3 patients $(n=116)$ were extracted from the database. None of the patients received neoadjuvant or perioperative radio-/chemotherapy.

\section{Pathological Evaluation}

All of the RC specimens were analyzed via central pathological review by dedicated genitourinary pathologists at our institution. The pathological staging of all specimens was reviewed and updated according to the 2002 TNM criteria; the WHO classification of 1973 was used for pathological grading. Lymphovascular invasion (LVI) was defined as the unequivocal presence of tumor cells within an endothelium-lined space with no underlying muscular walls [14]. A positive soft tissue surgical margin was defined as tumor at inked areas of soft tissue on the RC specimen. Urethral or ureteral margin status was not considered a margin.

\section{Immunohistochemistry}

Immunohistochemical staining for E-cad (1:50, No. M3612, clone NCH-38; Dako, Glostrup, Denmark) was conducted in all of the patients. Immunohistochemical evaluation was performed with a polymer-based detection system following optimized epitope retrieval. Sections were deparaffinized and rehydrated using deionized water. Afterwards, sections were heated in citrate buffer ( $\mathrm{pH}$ 6.0) using an electric pressure cooker for $3 \mathrm{~min}$ and cooled for 10 min before staining. The sections were then screened using an optical microscope to evaluate the E-cad staining pattern addressing homogeneity. Then, localization of E-cad was classified as nuclear, cytoplasmic or membrane associated. Finally, intensity was described as absent $(-)$, weak $(+)$, mild $(++)$ or strong $(+++)$.

\section{Follow-Up}

The median follow-up of patients alive at the end of the investigation was 15 months (interquartile range, IQR 7-32). Followup was performed according to current guidelines [3]. Patients were generally screened postoperatively at least every 3-4 months within the 1st year, semiannually for the 2 nd year and annually thereafter. Follow-up consisted of physical examination and serum chemistry evaluation. Diagnostic imaging of the upper urinary tract and chest X-rays were done at least annually or when clinically indicated. Additional radiographic evaluation, such as bone scan and/or computerized tomography, was conducted at the treating physician's discretion. Disease progression was defined as tumor relapse in the operative field, regional lymph nodes and/or distant metastasis. Urothelial carcinoma occurring in the ureter and/or urethra was regarded as a metachronous tumor and not coded as disease progression. Cause of death was determined by the treating physician, by chart review corroborated by death certificates or by death certificates alone [15]. All patients who were coded as having died of cancer had previous disease progression. Follow-up was recorded from the date of surgery until the last physical examination or death. The end points of the study were PFS, CSS and overall survival (OS), respectively.

\section{Statistical Analysis}

The Shapiro-Wilk normality test was used to analyze normal distribution of continuous variables. Continuous variables are shown as medians with IQR. The Wilcoxon rank sum (MannWhitney U) test was applied for nonnormally distributed variables. Comparisons between categorical variables were conducted using Fisher's exact test and the $\chi^{2}$ test.

Survival rates were estimated using the Kaplan-Meier method; the log-rank test was utilized for comparison of survival curves. 
Multivariable Cox regression models calculated in enter mode were performed to evaluate the influence of substaged pT3 UCB, the clinicopathological parameters age, gender, the American Association of Anesthesiologist score (ASA), carcinoma in situ, soft tissue surgical margins, lymph node involvement (LNI), LVI and E-cad expression on disease progression, cancer-specific and allcause mortality, respectively. The impact of the variables in the Cox models was assessed using the area under the receiver-operating characteristic curves.

Statistical analyses were performed with SPSS ${ }^{\circledR}$ Statistics 20 (SPSS, IBM Corp., Armonk, N.Y., USA) and R (version 3.0.0; The R Foundation for Statistical Computing, Vienna, Austria). Reported $\mathrm{p}$ values are two sided with the statistical significance level set at $\mathrm{p} \leq 0.05$.

\section{Results}

\section{Study Population}

A total of 74 patients $(63.8 \%)$ had pT3a and 42 patients (36.2\%) pT3b. Their median age was 73 years (IQR 63$77) ; 87(75 \%)$ patients were male and 29 (25\%) female. No statistically significant differences were found in clinicopathological features and E-cad expression in association with tumor substages (table 1), respectively. Most frequent urinary diversions accompanying RC were ileal conduit (59\%), ileal neobladder (30\%) and Indiana pouch $(4.5 \%)$.

\section{E-cad Expression in Stage pT3 UCB}

E-cad was expressed in 97 patients (83.6\%); 19 patients (16.4\%) did not express E-cad in the specimens analyzed. Intensity of E-cad staining in patients expressing E-cad was weak (+), mild (++) and strong $(+++)$ in 20,48 and $32 \%$ of the patients, respectively. About $94 \%$ of these patients showed a strict membranous expression of E-cad, and in $6.2 \%$ E-cad expression was only cytoplasmic (fig. 1). Neither intensity nor location of E-cad expression was significantly associated with any analyzed clinical or histopathological parameter (data not shown).

\section{Clinical Outcomes}

During follow-up, disease recurrence was observed in 60 patients $(51.7 \%)$, cancer-specific mortality in 50 patients $(43.1 \%)$, and 71 patients $(61.2 \%)$ died due to allcause mortality. In Kaplan-Meier analyses, both LNI ( $\mathrm{p}<$ $0.001)$ and LVI $(\mathrm{p}<0.001)$ were significantly associated with decreased PFS (fig. 2). With regard to CSS (fig. 3) and OS (fig. 4) estimates, ASA $3 / 4(\mathrm{p}=0.020$ and $\mathrm{p}=$ $0.003)$, LNI $(\mathrm{p}<0.001$ and $\mathrm{p}=0.008)$ and LVI $(\mathrm{p}<0.001$ and $\mathrm{p}=0.001)$, respectively, were associated with poor survival.
Table 1. Clinicopathological and immunohistochemical characteristics of 116 patients with pT3 UCB after RC

\begin{tabular}{|c|c|c|c|c|}
\hline \multirow[t]{2}{*}{ Parameter } & \multirow{2}{*}{$\begin{array}{l}\text { All } \\
\text { patients } \\
(\mathrm{n}=116)\end{array}$} & \multicolumn{3}{|l|}{ pT3 } \\
\hline & & $\begin{array}{l}\text { pT3a } \\
(\mathrm{n}=74)\end{array}$ & $\begin{array}{l}\text { pT3b } \\
(\mathrm{n}=42)\end{array}$ & $\begin{array}{l}\mathrm{p} \\
\text { value }\end{array}$ \\
\hline Median age, years & 73 & 70 & 68 & 0.646 \\
\hline IQR & $63-77$ & $64-77$ & $60-82$ & \\
\hline Gender & & & & 0.512 \\
\hline Male & $87(75.0)$ & $57(49.1)$ & $30(25.9)$ & \\
\hline Female & $29(25.0)$ & $17(14.7)$ & $12(10.3)$ & \\
\hline ASA & & & & 0.298 \\
\hline 1 & $23(20.7)$ & $15(13.5)$ & $8(7.2)$ & \\
\hline 2 & $44(39.6)$ & $31(27.9)$ & $13(11.7)$ & \\
\hline 3 & $43(38.7)$ & $23(20.7)$ & $20(18.0)$ & \\
\hline 4 & $1(0.9)$ & $1(0.9)$ & $0(0.0)$ & \\
\hline Lymph node status & & & & 0.330 \\
\hline Node-negative & $66(56.9)$ & $45(38.8)$ & $21(18.1)$ & \\
\hline Node-positive & $50(43.1)$ & $29(25.0)$ & $21(18.1)$ & \\
\hline LVI & & & & 0.697 \\
\hline Absent & $51(44.0)$ & $34(29.3)$ & $17(14.7)$ & \\
\hline Present & $65(56.0)$ & $40(34.5)$ & $25(21.6)$ & \\
\hline E-cad expression & & & & 0.436 \\
\hline Absent & $19(16.4)$ & $14(12.1)$ & $5(4.3)$ & \\
\hline Present & $97(83.6)$ & $60(51.7)$ & 37 (31.9) & \\
\hline E-cad intensity & & & & 0.679 \\
\hline- & $19(16.4)$ & $14(12.1)$ & $5(4.3)$ & \\
\hline+ & $20(17.2)$ & $11(9.5)$ & $9(7.8)$ & \\
\hline++ & $46(39.7)$ & $29(25.0)$ & $17(14.7)$ & \\
\hline+++ & $31(26.7)$ & $20(17.2)$ & $11(9.5)$ & \\
\hline E-cad localization & & & & 1.000 \\
\hline Cytoplasmic & $6(6.2)$ & $4(4.1)$ & $2(2.1)$ & \\
\hline Membranous & $91(93.8)$ & $56(57.7)$ & $35(36.1)$ & \\
\hline Carcinoma in situ & & & & 0.053 \\
\hline Absent & $60(51.7)$ & $33(28.4)$ & $27(23.3)$ & \\
\hline Present & $56(48.3)$ & $41(35.3)$ & 15 (12.9) & \\
\hline Soft tissue surgical manag & gement & & & 0.202 \\
\hline Negative & $105(90.5)$ & $69(59.5)$ & $36(31.0)$ & \\
\hline Positive & $11(9.5)$ & $5(4.3)$ & $6(5.2)$ & \\
\hline Urinary diversion & & & & 0.105 \\
\hline Ileal conduit & $71(61.2)$ & $42(36.2)$ & $29(25.0)$ & \\
\hline Indiana pouch & $5(4.3)$ & $4(3.4)$ & $1(0.9)$ & \\
\hline Ileal neobladder & $33(28.4)$ & $24(20.7)$ & $9(7.8)$ & \\
\hline Ureterocutaneostomy & $3(2.6)$ & $3(2.6)$ & $0(0.0)$ & \\
\hline Others & $4(3.4)$ & $1(0.9)$ & $3(2.6)$ & \\
\hline Administration of adjuvar & nt chemothe & rapy & & 0.799 \\
\hline Absent & $96(82.8)$ & $62(53.4)$ & $34(29.3)$ & \\
\hline Present & $20(17.2)$ & $12(10.3)$ & $8(6.9)$ & \\
\hline
\end{tabular}

Figures in parentheses are percentages. 


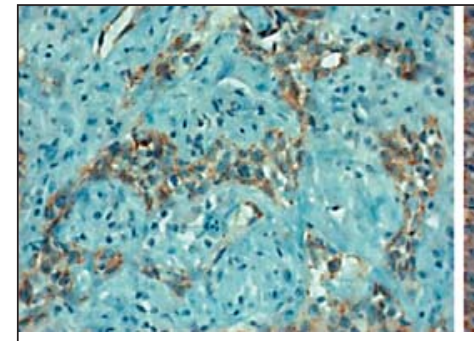

Cytoplasmic: $6 \%$

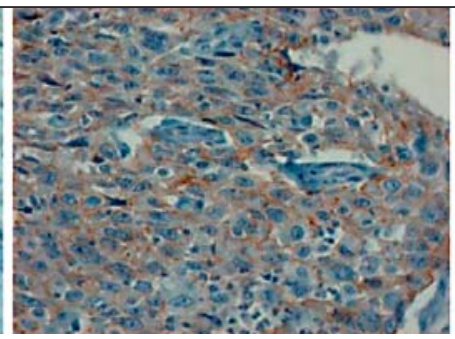

Weak: $20 \%$

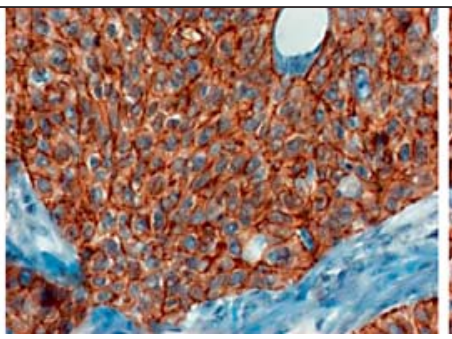

Membranous: $94 \%$

Mild: $48 \%$

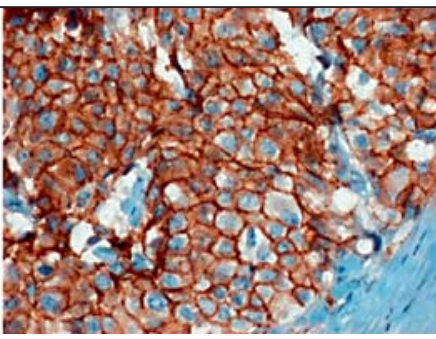

Strong: $32 \%$

Fig. 1. Localization, extent and frequency of E-cad immunohistochemical staining in stage pT3 UCB (magnification: $\times 400)$.
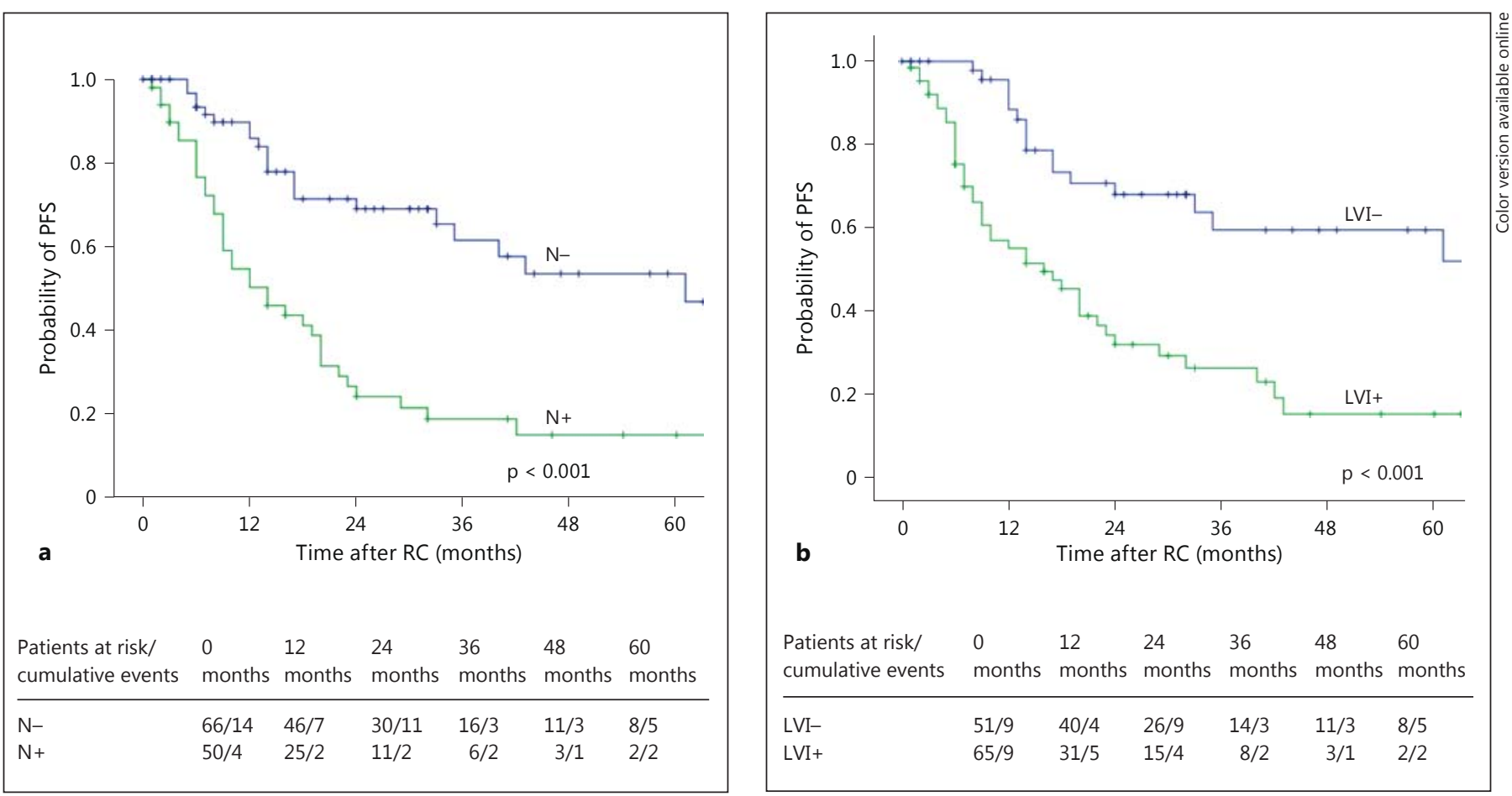

Fig. 2. Kaplan-Meier analysis estimating PFS according to LNI (a) and the absence (LVI-) or presence (LVI+) of LVI (b). N- = Nodenegative; $\mathrm{N}+=$ node-positive. The log-rank test was employed.

In multivariable Cox regression models calculated in enter mode, LNI (hazard ratio, HR 3.716, p < 0.001), LVI (HR 2.299, $\mathrm{p}=0.016)$ and administration of adjuvant chemotherapy (HR $0.36, \mathrm{p}=0.010$ ) significantly impacted disease progression. CSS and OS were independently influenced by ASA 3/4 (HR 1.82, p = 0.049, and HR 1.72, $\mathrm{p}=0.032)$, LNI (HR 4.57, $\mathrm{p}<0.001$, and HR 2.57, $\mathrm{p}=$
0.002 ) and administration of adjuvant chemotherapy (HR 0.28, p = 0.005, and HR 0.37, p =0.009), respectively (table 2). The area under the curve values for the models addressing disease progression, CSS and OS were 0.740, 0.724 and 0.701 , respectively. 


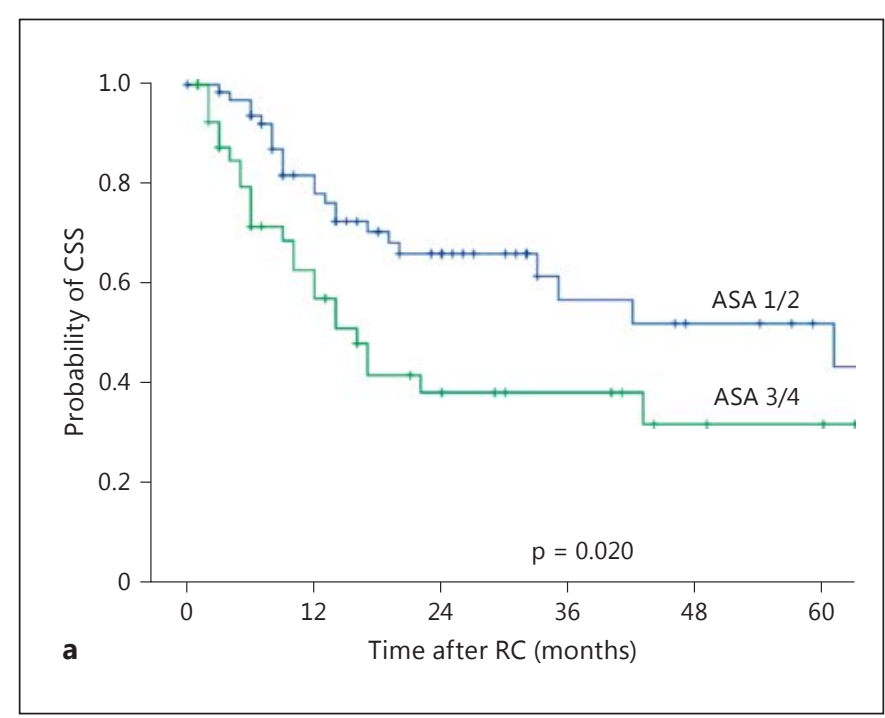

\begin{tabular}{|c|c|c|c|c|c|c|}
\hline $\begin{array}{l}\text { Patients at risk/ } \\
\text { cumulative events }\end{array}$ & $\begin{array}{l}0 \\
\text { months }\end{array}$ & $\begin{array}{l}12 \\
\text { months }\end{array}$ & $\begin{array}{l}24 \\
\text { months }\end{array}$ & $\begin{array}{l}36 \\
\text { months }\end{array}$ & $\begin{array}{l}48 \\
\text { months }\end{array}$ & $\begin{array}{l}60 \\
\text { months }\end{array}$ \\
\hline ASA $1 / 2$ & $67 / 12$ & $44 / 9$ & $27 / 13$ & $12 / 2$ & $9 / 3$ & $6 / 3$ \\
\hline $\begin{array}{l}\text { ASA } 3 / 4 \\
\mathbf{a}\end{array}$ & $44 / 8$ & $22 / 3$ & $11 / 3$ & $8 / 3$ & $4 / 1$ & $3 / 3$ \\
\hline
\end{tabular}

\begin{tabular}{|lllllll|}
\hline $\begin{array}{l}\text { Patients at risk/ } \\
\text { cumulative events }\end{array}$ & 0 & 12 & 24 & 36 & 48 & 60 \\
\hline months & months & months & months & months & months \\
\hline $\mathrm{N}+$ & $66 / 15$ & $46 / 7$ & $30 / 12$ & $16 / 4$ & $11 / 3$ & $8 / 5$ \\
b & $50 / 5$ & $25 / 6$ & $11 / 4$ & $6 / 2$ & $3 / 1$ & $2 / 2$ \\
\hline
\end{tabular}

\begin{tabular}{|lllllll|}
\hline $\begin{array}{l}\text { Patients at risk/ } \\
\text { cumulative events }\end{array}$ & 0 & 12 & 24 & 36 & 48 & 60 \\
& months & months & months & months & months & months \\
\hline LVI- & $51 / 9$ & $40 / 5$ & $26 / 10$ & $14 / 3$ & $11 / 3$ & $8 / 5$ \\
LVI+ & $65 / 11$ & $31 / 8$ & $15 / 6$ & $8 / 3$ & $3 / 1$ & $2 / 2$ \\
c & & & & & & \\
\hline
\end{tabular}

\section{Discussion}

The aim of the present study was to assess outcome predictors of patients suffering from pT3 UCB. Since in some trials, adjuvant chemotherapy is routinely administered [16], we sought to identify patients at high risk for poor oncological outcome who might profit from the administration of adjuvant chemotherapy and/or close surveillance after RC.

Outcome Prediction of pT3 UCB
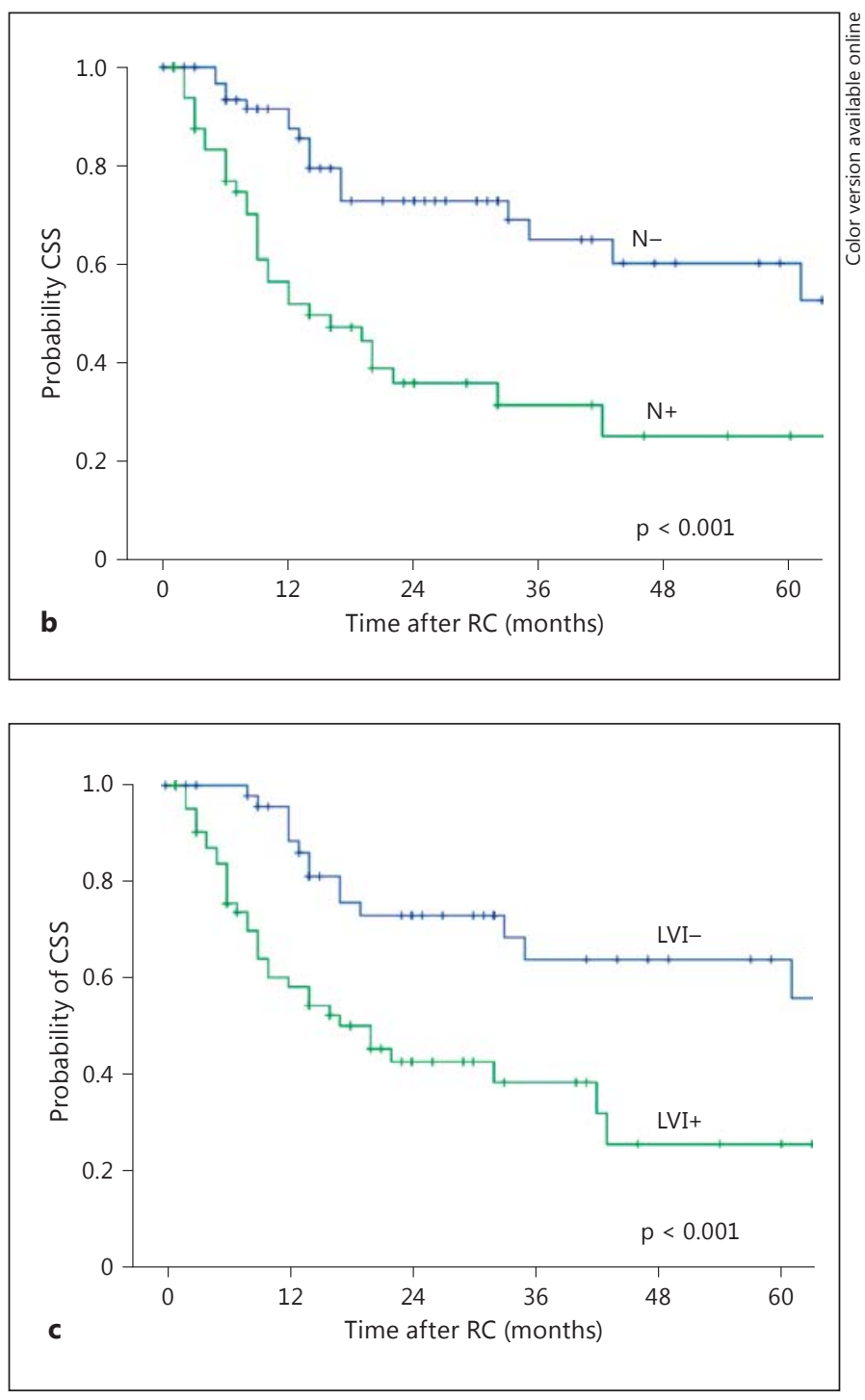

Fig. 3. Kaplan-Meier analysis estimating CSS according to ASA 3/4 (a), LNI (b) and the absence (LVI-) or presence (LVI+) of LVI (c). $\mathrm{N}-=$ Node-negative; $\mathrm{N}+=$ node-positive. The log-rank test was employed.

Since the AJCC/TNM substaging of pT3 UCB into microscopic (pT3a) and macroscopic (pT3b) infiltration of perivesical fat in 1997, this issue has formed the basis for many debates on bladder cancer in terms of the prognostic potential of the subdivided stage. The findings of our investigation demonstrate that regardless of LNI, pT3 substage has no independent impact on outcome after RC regarding progression and mortality. In line with our results, Quek et al. [5] found no statistical differences in 69 patients with pT3a versus 167 with pT3b UCB during a 


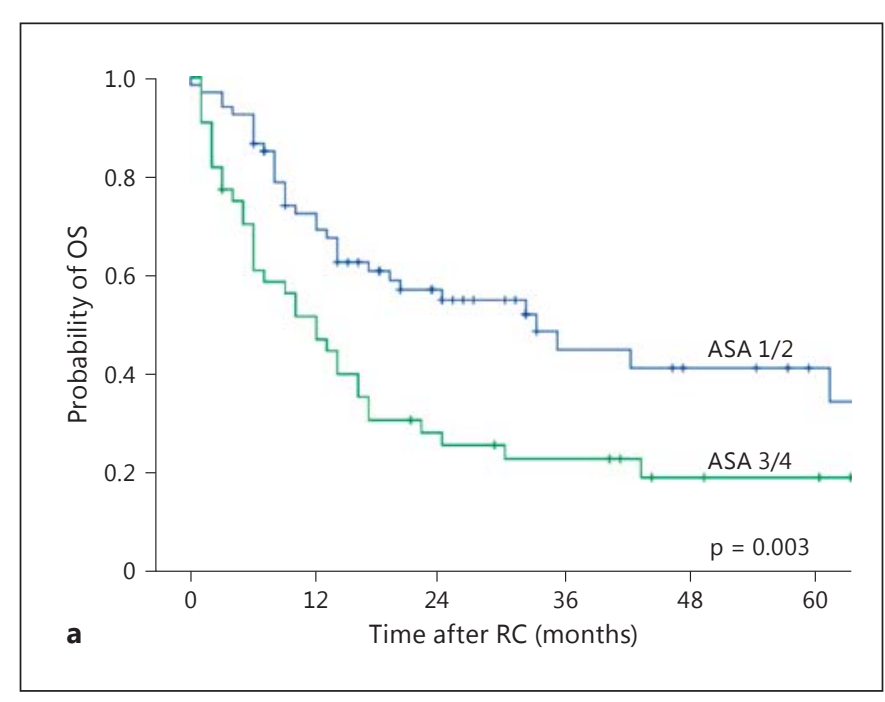

\begin{tabular}{|llllllll}
\hline $\begin{array}{l}\text { Patients at risk/ } \\
\text { cumulative events }\end{array}$ & 0 & 12 & 24 & 36 & 48 & 60 \\
& months & months & months & months & months & months \\
\hline ASA 1/2 & $67 / 5$ & $44 / 8$ & $27 / 11$ & $12 / 2$ & $9 / 3$ & $6 / 3$ \\
ASA 3/4 & $44 / 1$ & $22 / 1$ & $11 / 1$ & $8 / 3$ & $4 / 1$ & $3 / 3$ \\
a & & & & & & \\
\hline
\end{tabular}

\begin{tabular}{|lllllll|}
\hline \multirow{2}{*}{$\begin{array}{lllllll}\text { Patients at risk/ } \\
\text { cumulative events }\end{array}$} & 0 & 12 & 24 & 36 & 48 & 60 \\
& months & months & months & months & months & months \\
\hline $\mathrm{N}-$ & $66 / 15$ & $46 / 5$ & $30 / 9$ & $16 / 4$ & $11 / 3$ & $8 / 5$ \\
$\mathrm{~N}+$ & $50 / 1$ & $25 / 5$ & $11 / 3$ & $6 / 2$ & $3 / 1$ & $2 / 2$ \\
b & & & & & & \\
\hline
\end{tabular}

\begin{tabular}{|lllllll|}
\hline $\begin{array}{lllllll}\text { Patients at risk/ } \\
\text { cumulative events }\end{array}$ & 0 & 12 & 24 & 36 & 48 & 60 \\
& months & months & months & months & months & months \\
\hline LVI- & $51 / 3$ & $40 / 4$ & $26 / 7$ & $14 / 3$ & $11 / 3$ & $8 / 5$ \\
LVI+ & $65 / 3$ & $31 / 6$ & $15 / 5$ & $8 / 3$ & $3 / 1$ & $2 / 2$ \\
c & & & & & & \\
\hline
\end{tabular}

median follow-up of roughly 9 years. Bastian et al. [6] from the Bladder Cancer Research Consortium initially described a significant difference in recurrence and mortality between 210 patients staged pT3a versus pT3b, but this effect was evened out when adjusted for lymph node metastases. Tilki et al. [9] showed no statistical differences in outcome regarding pT3 substage in 808 patients. However, after inclusion of merely lymph node-negative patients $(n=456)$, gross tumor infiltration had a significant impact ( $\mathrm{p}=0.020$ vs. 0.048 ) on 5 -year recurrence-
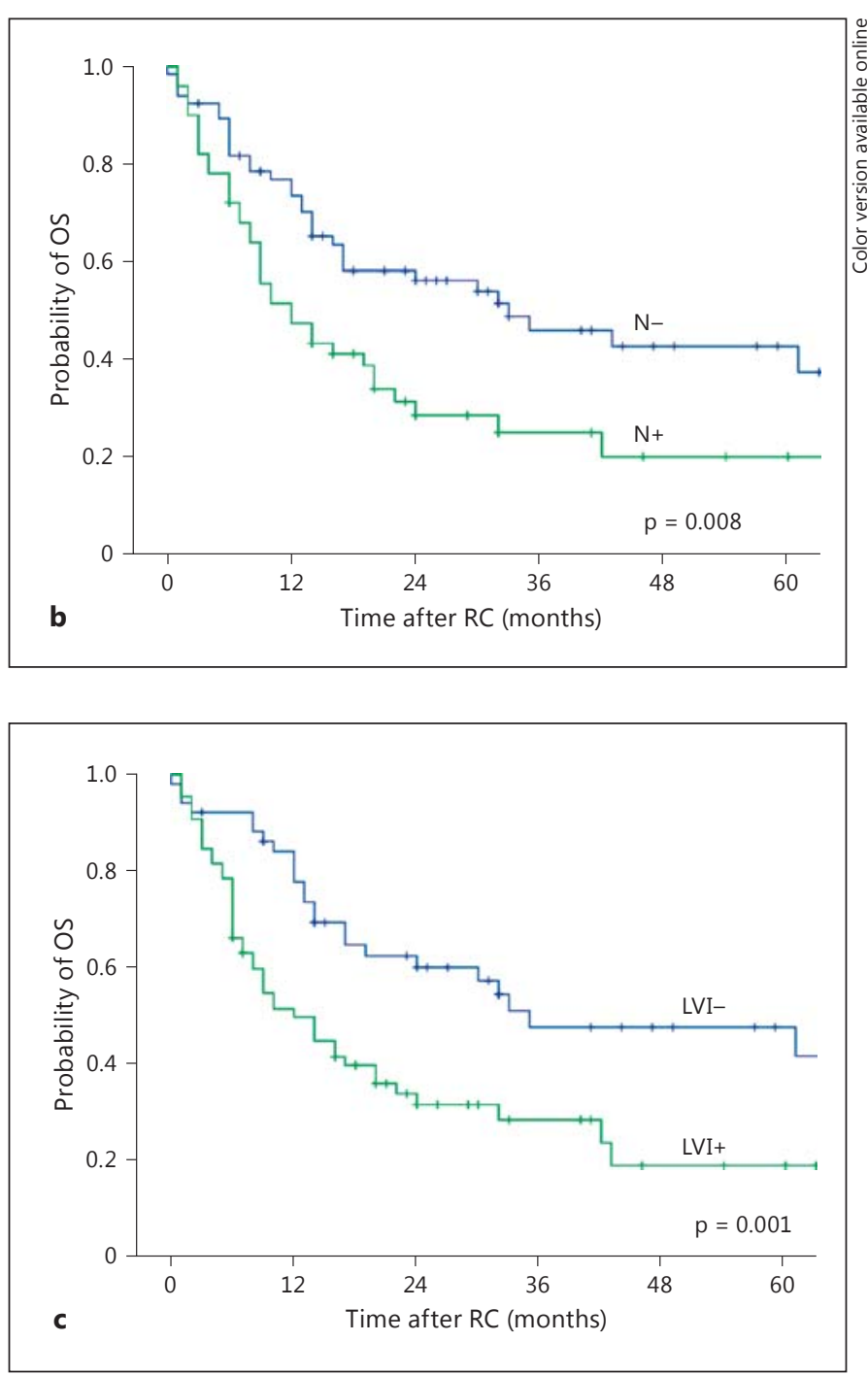

Fig. 4. Kaplan-Meier analysis estimating OS according to ASA 3/4 (a), LNI (b) and the absence (LVI-) or presence (LVI+) of LVI (c). $\mathrm{N}-=$ Node-negative; $\mathrm{N}+=$ node-positive. The log-rank test was employed.

free survival (60.7 vs. $47.9 \%$ ) and CSS (64.4 vs. 55.0\%) [9]. In order to diminish the potential bias of LNI, we calculated the same models after excluding all patients with positive lymph nodes $(\mathrm{n}=50)$ using multivariable Cox regression models. Similar to previous studies addressing this issue $[5,7,8]$, pT3 substage in our node-negative cohort of 66 patients had no independent impact on survival (data not shown).

LNI ( $p \leq 0.002)$ significantly affected all of our end points, while LVI $(\mathrm{p}=0.016)$ had an independent effect 
Table 2. Multivariable Cox regression models addressing PFS, CSS and OS in 116 patients with pT3 UCB after RC

\begin{tabular}{|c|c|c|c|c|c|c|c|c|c|}
\hline Parameter & \multicolumn{3}{|l|}{ PFS } & \multicolumn{3}{|l|}{ CSS } & \multicolumn{3}{|l|}{ OS } \\
\hline Female gender (ref.: male) & 0.917 & $0.490-1.716$ & 0.786 & 1.080 & $0.557-2.095$ & 0.820 & 0.930 & $0.530-1.632$ & 0.800 \\
\hline ASA 3/4 (ref.: ASA 1/2) & 1.495 & $0.854-2.618$ & 0.159 & 1.823 & $1.003-3.313$ & 0.049 & 1.720 & $1.047-2.825$ & 0.032 \\
\hline pT3a vs. pT3b & 0.905 & $0.489-1.672$ & 0.749 & 0.978 & $0.507-1.890$ & 0.948 & 1.248 & $0.738-2.111$ & 0.409 \\
\hline Small tissue surgical margin (present vs. absent) & 1.322 & $0.580-3.013$ & 0.506 & 0.965 & $0.357-2.605$ & 0.944 & 0.769 & $0.320-1.849$ & 0.557 \\
\hline LVI (present vs. absent) & 2.299 & $1.164-4.539$ & 0.016 & 1.713 & $0.842-3.486$ & 0.138 & 1.463 & $0.827-2.587$ & 0.191 \\
\hline E-cad expression (present vs. absent) & 1.041 & $0.396-2.735$ & 0.935 & 0.637 & $0.238-1.708$ & 0.371 & 0.636 & $0.301-1.341$ & 0.234 \\
\hline $\begin{array}{l}\text { Administration of adjuvant chemotherapy } \\
\text { (absent vs. present) }\end{array}$ & 0.356 & $0.162-0.779$ & 0.010 & 0.278 & $0.113-0.686$ & 0.005 & 0.365 & $0.171-0.780$ & 0.009 \\
\hline
\end{tabular}

CIS $=$ Carcinoma in situ; $\mathrm{LN}=$ lymph node .

on PFS. In our calculations, LVI and LNI were both tested for collinearity and displayed a $\varphi$ value $<0.55$ ( $p<$ 0.001 ), thus allowing us to integrate both of the features in the same model. In line with Quek et al. [5], we could not see a significant association between the distribution of tumor substage and LNI $(\mathrm{p}=0.33)$. In the study by Tilki et al. [9], both LVI ( $p \leq 0.014)$ and LNI $(p<0.001)$ had a significant impact on disease recurrence and CSS, respectively, regardless of lymph node status. The value of LVI in outcome prediction in pT3 UCB was utilized through its integration into prognostic assessment tools $[10,11]$. Currently, LNI remains the strongest predictor of outcome in UCB regardless of stage. Our findings mirror those of the vast majority of studies in UCB ascribing positive nodal stage a poor outcome after RC [17-22].

ASA was shown to be a strong predictor of CSS and OS in our cohort. In contrast to all of the studies that address the matter of outcome prediction in substaged pT3 UCB published to date, we were able to demonstrate that ASA $3 / 4$ is an independent predictor of survival for the first time. Comorbidity plays a large role in the treatment and follow-up of patients with RC due to UCB [23]. Mayr et al. [23] investigated the impact of severe comorbidity and performance indices on outcome in patients with UCB after RC with regard to cancer-independent mortality. In their multicenter multinational study, they found a significant impact of ASA on cancer-independent mortality $(\mathrm{p}=0.001)$ in Cox regression models. In our population, ASA 3/4 patients had a 1.7-fold higher risk of all-cause mortality $(p=0.032)$ and a 1.8-fold higher risk of cancer- specific mortality $(\mathrm{p}=0.049)$. Thus, $\mathrm{pT} 3$ patients with ASA 3/4 should be monitored closely after RC, with modification to surveillance as required.

In addition to the established clinicopathological markers addressing outcome prediction in UCB patients after RC, we added the immunohistochemical marker E-cad to our calculations due to its potential predictive capacity. Decreased E-cad expression is associated with a high risk of tumor progression [24] and poor CSS, respectively [25]. However, several studies failed to find an independent impact of the E-cad expression pattern on the prognosis of UCB patients [26, 27]. Expression of E-cad did not influence prognostic outcome after RC in our population of pT3 UCB both with and without taking lymph node-negative patients into account. A potential explanation could be found in the differences in immunohistochemical staining and analysis procedures, since our study only classified specimens with a strict loss of E-cad as E-cad negative. Nevertheless, we currently have no explanation for the lack of impact of E-cad on outcome after RC.

The administration of adjuvant chemotherapy could benefit patients with locally advanced UCB, but is generally recommend within clinical trials [3]. However, our study could not find a significant benefit of adjuvant chemotherapy administration on survival (data not shown), in agreement with the findings of Tilki et al. [9]. Despite the small number of patients receiving adjuvant chemotherapy $(n=20)$, we were able to determine an independent influence of adjuvant chemotherapy on outcome. We therefore recommend consideration of adjuvant che- 
motherapy in patients with positive lymph node status and/or presence of LVI. Moreover, information on the presence of LVI, ASA status and clinically suspected positive lymph node stage at the time of the last transurethral resection of bladder tumor before $\mathrm{RC}$ might facilitate the stratification of patients for neoadjuvant chemotherapy. Further studies are warranted, preferably prospective studies, to address this issue.

Our study is not devoid of limitations. First and foremost, there are limitations inherent to retrospective studies. Another limitation is the lack of neoadjuvant chemotherapy administration despite recent recommendations [3], which could compromise comparability to future data. The major limitation is the cohort size included in our investigation. However, this was a single-center study with a small of number of experienced surgeons and standard surgery procedures established over years. Furthermore, a central pathology review was not performed, thus minimizing the potential bias of an interobserver variability between pathologists. Moreover, all surgeons and pathologists at our institution are dedicated to the management of RC.

\section{Conclusions}

The findings of our study demonstrate that both pT3 substage and E-cad expression did not impact on outcome prediction after RC for patients with pT3 UCB. In clinical decision making for this heterogeneous group of UCB patients, we strongly recommend taking positive lymph node status, LVI and ASA 3/4 into account for the administration of adjuvant chemotherapy and modification of surveillance after RC. Our results ideally need to be validated within a robust, prospective cohort.

\section{Acknowledgment}

We are grateful to Stefanie Goetz and Patrick Goldsworthy for their valuable assistance.

\section{References}

1 Jemal A, Siegel R, Xu J, Ward E: Cancer statistics, 2010. CA Cancer J Clin 2010;60:227-300.

2 Howlader N, Noone AM, Krapcho M, et al: SEER Cancer Statistics Review, 1975-2009 (Vintage 2009 Populations). Bethesda, National Cancer Institute, 2012.

- 3 Stenzl A, Cowan NC, De Santis M, Kuczyk MA, Merseburger AS, Ribal MJ, Sherif A, Witjes JA; European Association of Urology (EAU): Treatment of muscle-invasive and metastatic bladder cancer: update of the EAU guidelines. Eur Urol 2011;59:1009-1018.

4 Greene FL, Page DL, Fleming ID, et al: AJCC Cancer Staging Manual, ed 6. Philadelphia, Lippincott-Raven, 2002.

5 Quek ML, Stein JP, Clark PE, Daneshmand S, Miranda G, Cai J, Groshen S, Cote RJ, Lieskovsky G, Quinn DI, Skinner DG: Microscopic and gross extravesical extension in pathological staging of bladder cancer. J Urol 2004; 171:640-645.

6 Bastian PJ, Hutterer GC, Shariat SF, Rogers CG, Palapattu GS, Lotan Y, Vazina A, Amiel GE, Gupta A, Sagalowsky AI, Lerner SP, Schoenberg MP, Karakiewicz PI; Bladder Cancer Research Consortium: Macroscopic, but not microscopic, perivesical fat invasion at radical cystectomy is an adverse predictor of recurrence and survival. BJU Int 2008; 101 : 450-454.
7 Boudreaux KJ Jr, Chang SS, Lowrance WT, Rumohr JA, Barocas DA, Cookson MS, Smith JA Jr, Clark PE: Comparison of American Joint Committee on Cancer pathologic stage T3a versus T3b urothelial carcinoma: analysis of patient outcomes. Cancer 2009;115:770775.

-8 Dincel C, Kara C, Balci U, Ozer K, Ozbir S, Sefik E, Gorgel SN, Girgin C: Comparison of microscopic (pT3a) and gross extravesical extension (pT3b) in pathological staging of bladder cancer: analysis of patient outcomes. Int Urol Nephrol 2013;45:387-393.

-9 Tilki D, Svatek RS, Karakiewicz PI, Novara G, Seitz M, Sonpavde G, Gupta A, Kassouf W, Fradet Y, Ficarra V, Skinner E, Lotan Y, Sagalowsky AI, Stief CG, Reich O, Shariat SF: pT3 substaging is a prognostic indicator for lymph node negative urothelial carcinoma of the bladder. J Urol 2010;184:470-474.

10 Sonpavde G, Khan MM, Svatek RS, Lee R, Novara G, Tilki D, Lerner SP, Amiel GE, Skinner E, Karakiewicz PI, Bastian PJ, Kassouf W, Fritsche HM, Izawa JI, Scherr DS, Ficarra V, Dinney CP, Lotan Y, Fradet Y, Shariat SF: Prognostic risk stratification of pathological stage T3N0 bladder cancer after radical cystectomy. J Urol 2011;185:12161221.
11 May M, Bastian PJ, Brookman-May S, Fritsche HM, Bolenz C, Gilfrich C, Otto W, Trojan L, Herrmann E, Müller SC, Ellinger J, Buchner A, Stief CG, Tilki D, Wieland WF, Hohenfellner M, Haferkamp A, Roigas J, Zacharias M, Nuhn P, Burger M: External validation of a risk model to predict recurrence-free survival after radical cystectomy in patients with pathological tumor stage T3N0 urothelial carcinoma of the bladder. J Urol 2012;187:1210-1214

12 Jeanes A, Gottardi CJ, Yap AS: Cadherins and cancer: how does cadherin dysfunction promote tumor progression? Oncogene 2008;27: 6920-6929.

13 Kashibuchi K, Tomita K, Schalken JA, Kume $\mathrm{H}$, Takeuchi T, Kitamura T: The prognostic value of E-cadherin, alpha-, beta- and gamma-catenin in bladder cancer patients who underwent radical cystectomy. Int J Urol 2007;14:789-794

14 Lotan Y, Gupta A, Shariat SF, Palapattu GS, Vazina A, Karakiewicz PI, Bastian PJ, Rogers CG, Amiel G, Perotte P, Schoenberg MP, Lerner SP, Sagalowsky AI: Lymphovascular invasion is independently associated with overall survival, cause-specific survival, and local and distant recurrence in patients with negative lymph nodes at radical cystectomy. J Clin Oncol 2005;23:6533-6539. 
15 Rink M, Fajkovic H, Cha EK, Gupta A, Karakiewicz PI, Chun FK, Lotan Y, Shariat SF: Death certificates are valid for the determination of cause of death in patients with upper and lower tract urothelial carcinoma. Eur Urol 2012;61:854-855.

16 Shariat SF, Karakiewicz PI, Palapattu GS, Lo$\tan$ Y, Rogers CG, Amiel GE, Vazina A, Gupta A, Bastian PJ, Sagalowsky AI, Schoenberg MP, Lerner SP: Outcomes of radical cystectomy for transitional cell carcinoma of the bladder: a contemporary series from the Bladder Cancer Research Consortium. J Urol 2006;176:2414-2422.

17 Buscarini M, Josephson DY, Stein JP: Lymphadenectomy in bladder cancer: a review. Urol Int 2007;79:191-199.

18 Rabbani F, Lee C, Chang SS, Lerner SP, Wood DP, Herr HW: Accuracy of the extent of bladder cancer nodal metastases found at pelvic lymphadenectomy at the time of cystectomy: relation to primary tumor stage. Urol Int 2010;84:14-22.

19 Novara G, Ficarra V, Alrabi N, Dalpiaz O, Martignoni G, Galfano A, Cavalleri S, Artibani W: Prognostic factors in a recent series of patients treated with radical cystectomy for bladder cancer. Urol Int 2005;75:10-16.
20 Fritsche HM, May M, Denzinger S, Otto W, Siegert S, Giedl C, Giedl J, Eder F, Agaimy A, Novotny V, Wirth M, Stief C, Brookman-May S, Hofstädter F, Gierth M, Aziz A, Kocot A, Riedmiller H, Bastian PJ, Toma M, Wieland WF, Hartmann A, Burger M: Prognostic value of perinodal lymphovascular invasion following radical cystectomy for lymph nodepositive urothelial carcinoma. Eur Urol 2013; 63:739-744.

21 May M, Herrmann E, Bolenz C, Tiemann A, Brookman-May S, Fritsche HM, Burger M, Buchner A, Gratzke C, Wülfing C, Trojan L, Ellinger J, Tilki D, Gilfrich C, Höfner T, Roigas J, Zacharias M, Gunia S, Wieland WF, Hohenfellner M, Michel MS, Haferkamp A, Müller SC, Stief CG, Bastian PJ: Lymph node density affects cancer-specific survival in patients with lymph node-positive urothelial bladder cancer following radical cystectomy. Eur Urol 2011;59:712-718

22 Gierth M, Fritsche HM, Buchner H, May M, Aziz A, Otto W, Bolenz C, Trojan L, Hermann E, Tiemann A, Müller SC, Ellinger J, Brookman-May S, Stief CG, Tilki D, Nuhn P, Höfner T, Hohenfellner M, Haferkamp A, Roigas J, Zacharias M, Wieland WF, Riedmiller $\mathrm{H}$, Denzinger S, Bastian PJ, Burger M: Clinical and pathological nodal staging score for urothelial carcinoma of the bladder: an external validation. World J Urol 2014;32:365-371.
23 Mayr R, May M, Martini T, Lodde M, Comploj E, Pycha A, Strobel J, Denzinger S, Otto W, Wieland W, Burger M, Fritsche HM: Comorbidity and performance indices as predictors of cancer-independent mortality but not of cancer-specific mortality after radical cystectomy for urothelial carcinoma of the bladder. Eur Urol 2012;62:662-670.

24 Morton RA Jr, Ewing CM, Watkins JJ, Isaacs WB: The E-cadherin cell-cell adhesion pathway in urologic malignancies. World J Urol 1995;13:364-368.

25 Byrne RR, Shariat SF, Brown R, Kattan MW, Morton RA Jr, Wheeler TM, Lerner SP: E-cadherin immunostaining of bladder transitional cell carcinoma, carcinoma in situ and lymph node metastases with long-term followup. J Urol 2001;165:1473-1479.

26 Lipponen PK, Eskelinen MJ: Reduced expression of E-cadherin is related to invasive disease and frequent recurrence in bladder cancer. J Cancer Res Clin Oncol 1995;121:303308.

27 Mialhe A, Louis J, Montlevier S, Peoch M, Pasquier D, Bosson JL, Rambeaud JJ, Seigneurin D: Expression of E-cadherin and alpha-, beta- and gamma-catenins in human bladder carcinomas: are they good prognostic factors? Invasion Metastasis 1997;17:124-137. 